\title{
Memory T cells delay the progression of atherosclerosis via AMPK signaling pathway
}

\author{
Li-Ping Peng ${ }^{1 \#}$, Yu Cao ${ }^{1 \#}$, Shao-Li Zhao ${ }^{2 \#}$, Yu-Xi Huang ${ }^{3}$, Kan Yang ${ }^{1}$, Wei Huang ${ }^{1}$ \\ ${ }^{1}$ Department of Cardiology, ${ }^{2}$ Department of Endocrine, ${ }^{3}$ Department of Nephrology, The Third Xiangya Hospital of Central South University, \\ Changsha 410013, China \\ Contributions: (I) Conception and design: LP Peng, Y Cao, SL Zhao; (II) Administrative support: Y Cao; (III) Provision of study materials or patients: \\ All authors; (IV) Collection and assembly of data: LP Peng, Y Cao, SL Zhao; (V) Data analysis and interpretation: LP Peng, Y Cao, SL Zhao; (VI) \\ Manuscript writing: All authors; (VII) Final approval of manuscript: All authors. \\ \#These authors contributed equally to this work. \\ Correspondence to: Dr. Yu Cao. Department of Cardiology, The Third Xiangya Hospital of Central South University, Changsha 410013, China. Email: \\ 13787318063@139.com; Dr. Shao-li Zhao. Department of Endocrine, The Third Xiangya Hospital of Central South University, Changsha 410013, \\ China. Email: zslplp@163.com.
}

Background: Memory T cells play a key role in the development of atherosclerosis (AS). This study aimed to investigate the role of AMPK signaling pathway of spleen memory T cells in the pathogenesis of AS in high-fat diet (HFD) fed mice.

Methods: Mice were divided into 5 groups: normal group, AS group, AS + solvent group, AS + Compound C (AMPK inhibitor) group and AS + A-769662 (AMPK agonist) group. HFD animals were intraperitoneally treated with Compound C at $20 \mathrm{mg} / \mathrm{kg}$ thrice weekly or A-769662 at $30 \mathrm{mg} / \mathrm{kg}$ once daily for 15 weeks. Then, the degree of AS was assessed, and the proportion of memory $\mathrm{T}$ cell was determined by flow cytometry.

Results: AS was evident in the aorta of HFD mice. The areas of plaque formation in both AS + Compound C group and AS + A-769662 group reduced as compared to the AS group and AS + solvent group. After intervention of AMPK activity, the proportion of memory $\mathrm{T}$ cells in the spleen reduced as compared to the AS group and AS + solvent group; the pro proportion of memory T cells in HFD groups was markedly higher than in the normal group and this increase was more evident in the AS + Compound $\mathrm{C}$ than in the AS + A-769662 group.

Conclusions: The decreased memory $\mathrm{T}$ cells can improve AS, which may be related to the AMPK signaling pathway. Thus, AMPK in the memory $\mathrm{T}$ cells may serve as a target in the prevention and treatment of AS.

Keywords: Memory T cells; AMP activated protein kinase; atherosclerosis (AS); naïve T lymphocytes

Submitted Jul 07, 2019. Accepted for publication Oct 24, 2019.

doi: 10.21037/atm.2019.11.20

View this article at: http://dx.doi.org/10.21037/atm.2019.11.20

\section{Introduction}

Cardiovascular and cerebrovascular diseases have become the leading cause of death worldwide. Atherosclerosis (AS), a chronic inflammatory disease, is also a common important preclinical pathology of cardiovascular and cerebrovascular diseases. Some studies have shown that memory T cells play an important role in the chronic inflammation in the pathogenesis of AS. It has been reported $(1,2)$ that memory $\mathrm{T}$ cell subsets present a sustained immune response in case of AS, and the antigens produced in this period are specific (3-5). A recent multi-ethnic, cross-sectional epidemiological study (6) indicates CD4 memory cells are associated with the extent of subclinical AS. 
AMP activated protein kinase (AMPK) is a heterotrimeric protein composed of alpha catalytic subunit and $\beta$ and $\gamma$ regulatory subunits. It is widely distributed in the myocardium, fat, skeletal muscle, pancreas and central nervous system. There is evidence showing that AMPK is related to the pathogenesis of a variety of cardiovascular diseases by affecting the proliferation and differentiation of cardiomyocytes, smooth muscle cells and endothelial cells via different pathways. AMPK can bind to AMPK receptor to regulate the functions of $\mathrm{T}$ cells. However, whether AMPK can affect the occurrence and development of AS by regulating memory $\mathrm{T}$ cells has not been studied, and, if so, the specific mechanism is unclear.

\section{Methods}

\section{Animals}

Eight-week-old ApoE ${ }^{-/-}$male mice (Strain code: BCGDIS-0002) were housed in the specific pathogen-free (SPF) environment. Animals were divided into 5 groups: AS group, AS + solvent group, AS + Compound C (AMPK inhibitor) group, AS + A-769662 (AMPK agonist) group ( $\mathrm{n}=5$ per group). All the mice were allowed to accommodate to the environment for 1 week. Then, the mice in the highfat diet (HFD) group were fed with high-fat diet [10\% lard $+4 \%$ milk powder $+1.25 \%$ cholesterol $+0.5 \%$ sodium cholate $+84.25 \%$ basic diet (wheat, corn, salt, eggs, cypress, trace elements)] for 15 weeks. Animals in the normal control group were fed with normal diet. All the animals were given ad libitum access to water. After 15-week HFD, the aorta was collected and processed for further analysis.

AMPK inhibitor Compound $\mathrm{C}$ was dissolved in $2 \mathrm{~mL}$ of normal saline. In the AS + Compound C, HFD treated animals were intraperitoneally treated with Compound $\mathrm{C}$ at $20 \mathrm{mg} / \mathrm{kg}$ thrice weekly (7). AMPK agonist A-769662 was dissolved in $2 \mathrm{~mL}$ of normal saline. In the AS + A-769662 group, HFD treated animals were intraperitoneally treated with A-769662 at $30 \mathrm{mg} / \mathrm{kg}$ once daily (8). In the AS + solvent, animals were intraperitoneally treated with normal saline of equal amount once daily.

\section{Flow cytometry}

The spleen cells were collected and the supernatant was removed after centrifugation at room temperature for $5 \mathrm{~min}$ at $350 \mathrm{~g}$. After re-suspension in $100 \mu \mathrm{L}$ of PBS, FITCCD4 and PE-CD44 antibodies were added, followed by incubation for $15 \mathrm{~min}$ at $4{ }^{\circ} \mathrm{C}$ in dark. The cells were washed once with $3 \mathrm{~mL}$ of $0.5 \%$ BSA-PBS, and then centrifuged at room temperature for $5 \mathrm{~min}$ at $350 \mathrm{~g}$. After removal of the supernatant, cells were re-suspended in $400 \mu \mathrm{L}$ of $0.5 \%$ BSA-PBS for flow cytometry.

\section{Western blotting}

The mouse spleen cells were washed once with ice-cold PBS and then incubated with $50 \mu \mathrm{L}$ of RIPA lysis buffer. After centrifugation at 3,000 rpm for $2 \mathrm{~min}$, the supernatant was removed, and $50 \mu \mathrm{L}$ of RIP lysis buffer was added, followed by incubation on ice for $10 \mathrm{~min}$. After centrifugation at $12,000 \mathrm{rpm}$ for $15 \mathrm{~min}$ at $4{ }^{\circ} \mathrm{C}$, the supernatant was collected and the protein concentration was determined. Proteins of equal amount were loaded for SDS-PAGE and then transferred onto the nitrocellulose membrane. The membrane was then incubated in 5\% non-fat milk solution. After blocking at room temperature for $1.5 \mathrm{~h}$, the membrane was rinsed with TBST and then incubated with primary antibody overnight at $4^{\circ} \mathrm{C}$. After washing in TBST, the membrane was incubated with secondary antibody (anti-rabbit: 1:6,000, anti-mouse: 1:5,000) for $90 \mathrm{~min}$ at room temperature. After washing in TBST thrice $(5 \mathrm{~min}$ for each), visualization was done with chemiluminescence. Protein bands were scanned, and the optical density was analyzed.

\section{Oil red $O$ staining and $H E$ staining}

The aorta was collected from the aortic arch of the abdominal aorta (at the level of renal artery), and the surrounding adipose tissues were removed. The aorta was cut longitudinally and fixed in $4 \%$ paraformaldehyde overnight. The aortic tissues were then subjected to oil red $\mathrm{O}$ staining for $10 \mathrm{~min}$ at room temperature. The remaining tissues were embedded in the paraffin, and then sectioned. After deparaffinization, sections were dehydrated and stained with hematoxylin for 8-10 s and then with eosin for 2-3 s. After dehydration, sections were mounted with neutral gum.

\section{Study design}

This study was approved by the Institutional Ethics Committee of the Third Xiangya Hospital of Central South University (No: 2015-S175). 
Table 1 Blood lipids and glucose at the end of study

\begin{tabular}{|c|c|c|c|c|c|}
\hline $\begin{array}{l}\text { Parameters } \\
(\mathrm{mmol} / \mathrm{L})\end{array}$ & $\begin{array}{l}\text { Normal control } \\
\text { group }(n=5)\end{array}$ & $\begin{array}{l}\text { AS group } \\
\quad(n=5)\end{array}$ & $\begin{array}{l}\text { AS + Compound } \\
\text { C group }(n=5)\end{array}$ & $\begin{array}{c}A S+A-769662 \\
\text { group }(n=5)\end{array}$ & $\begin{array}{l}\text { AS + solvent } \\
\text { group }(n=5)\end{array}$ \\
\hline TC & $1.14 \pm 0.25$ & $4.06 \pm 0.23^{\star}$ & $3.93 \pm 0.20^{\star}$ & $4.07 \pm 0.16^{\star}$ & $4.07 \pm 0.21^{*}$ \\
\hline LDL-C & $0.36 \pm 0.23$ & $12.37 \pm 2.13^{*}$ & $10.52 \pm 0.4^{\star^{\mathbf{\Lambda}}}$ & $14.23 \pm 0.91^{*}$ & $12.77 \pm 1.17^{\star}$ \\
\hline HDL & $27.56 \pm 2.55$ & $53.30 \pm 14.5^{\star}$ & $37.09 \pm 6.52^{*}$ & $51.37 \pm 11.69^{*}$ & $51.01 \pm 8.57^{*}$ \\
\hline ox-LDL & $0.96 \pm 0.17$ & $2.10 \pm 0.23^{*}$ & $1.89 \pm 0.26^{\star}$ & $2.10 \pm 0.19^{\star}$ & $2.10 \pm 0.34^{*}$ \\
\hline
\end{tabular}

TC, cholesterol; TG, triglyceride; LDL-C, low density lipoprotein cholesterol; HDL, high density lipoprotein; BS, blood glucose; ox-LDL, oxidized low density lipoprotein; AS, atherosclerosis. ${ }^{*}, \mathrm{P}<0.05$ : AS group vs. normal control group $(\mathrm{P}<0.05)$. ${ }^{\mathbf{A}}, \mathrm{P}<0.05$ : compound $\mathrm{C}$ group vs. A-769662 group $(\mathrm{P}<0.05)$.
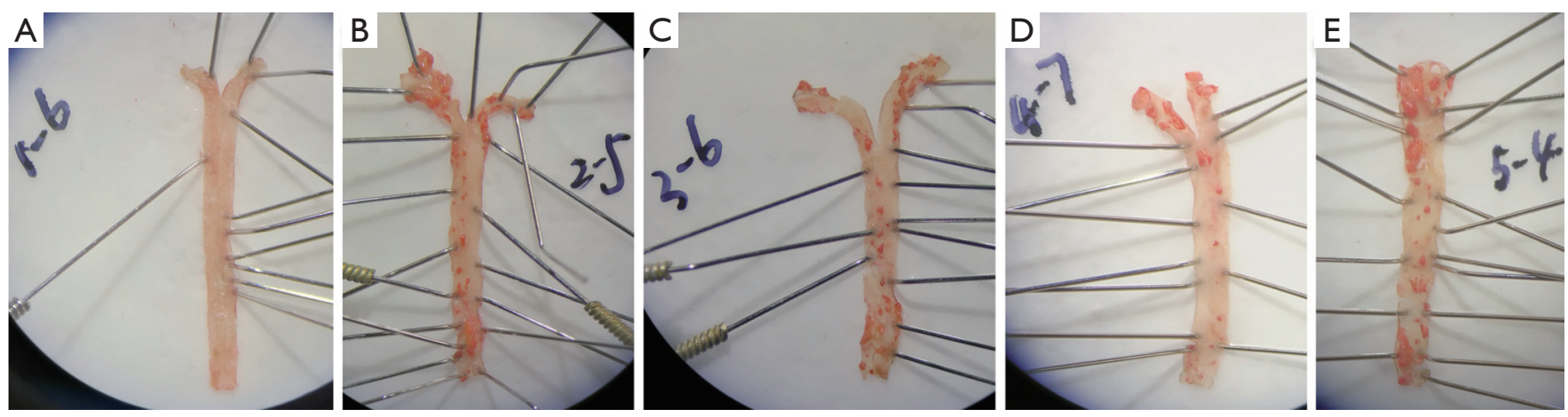

Figure 1 Oil red O staining of the aorta. There were obvious red plaques in the aorta of HFD treated mice, and the plaque was larger near the aortic arch and the abdominal aorta (tail). (A) Normal control group; (B) AS group; (C) AS + Compound C group; (D) AS + A-769662 group; (E) AS + solvent group. AS, atherosclerosis; HFD, high-fat diet.

\section{Statistical analysis}

Statistical analysis was performed with SPSS version 19.0 and data are expressed as mean \pm standard deviation $(\mathrm{SD})$. After testing the homogeneity of the variance, data were compared with $t$-test between two groups or one-way analysis of variance (ANOVA) among groups followed by Student-Newman-Keuls test between groups. A value of $\mathrm{P}<0.05$ was considered statistically significant.

\section{Results}

\section{Blood lipids, blood glucose and ox-LDL in each group}

The total cholesterol, low-density lipoprotein, high-density lipoprotein, triglyceride, blood glucose and ox-LDL of the HFD treated mice were significantly higher than in the mice fed with normal diet $(\mathrm{P}<0.05)$ (Table 1). The
LDL-C and triglyceride in the AS + Compound C group were significantly lower than in the AS + A-769662 group $(\mathrm{P}<0.05)$ (Table 1). This suggests that AMPK can may affect the lipid metabolism.

\section{Oil red $O$ staining of the aorta}

No red plaques were observed in the aorta of normal control group. However, the red plaques were obvious in the aorta of HFD treated mice, and the plaque was larger near the aortic arch and the abdominal aorta (tail). In addition, the area of plaques in the AS group and AS + solvent group was larger than in the AS + Compound $\mathrm{C}$ group and the AS + A-769662 group (Figure 1). This is suggested that both AMPK agonist and AMPK inhibitor can improve the AS. 

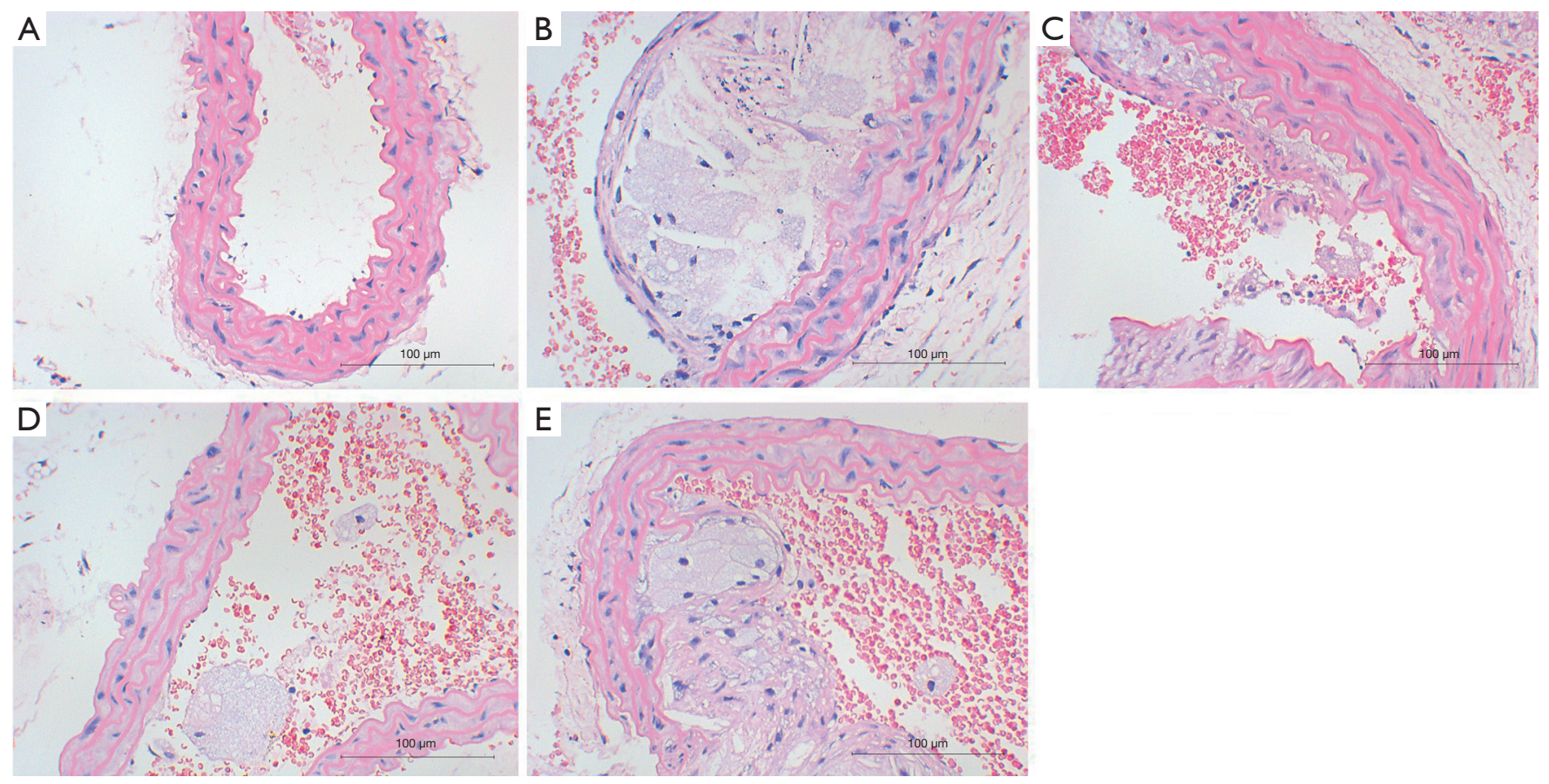

Figure $2 \mathrm{HE}$ staining of the aorta in different groups. Both AMPK agonist and AMPK inhibitor improved AS. (A) Normal control group; (B) AS group; (C) AS + Compound C group; (D) AS + A-769662 group; (E) AS + solvent group. AS, atherosclerosis.

Table 2 Flow cytometry of spleen CD4+CD44+ lymphocytes in different groups ( $\mathrm{n}=5$ per group)

\begin{tabular}{|c|c|}
\hline Groups & Proportion of CD4+CD44+ lymphocytes (\%) \\
\hline Normal control & $1.38 \pm 1.42$ \\
\hline AS group & $4.32 \pm 1.55^{\star^{\Lambda}}$ \\
\hline AS + Compound C & $2.02 \pm 1.77^{\star}$ \\
\hline$A S+A-769662$ & $3.91 \pm 1.57^{*}$ \\
\hline AS + solvent & $5.01 \pm 0.74^{\star^{\boldsymbol{\Lambda}}}$ \\
\hline
\end{tabular}

\section{HE staining of the aorta}

HE staining showed the mucosal degeneration and edema of the vascular wall in the HFD treated mice, and typical atherosclerotic plaque was noted in the vascular wall. The lipid cores were thicker in the AS model group and the $\mathrm{AS}+$ solvent group, and foamed lipids were evident. The lipid cores in the AS + Compound C group and the AS + A-769662 group were significantly improved as compared to the AS group and AS + solvent group (Figure 2). This is suggested both AMPK agonist and AMPK inhibitor can improve AS.

\section{Flowcytometry of spleen lymphocytes}

Flow cytometry showed that the proliferation rate of CD4+CD44+ memory $\mathrm{T}$ cells in the normal control group was low $(1.38 \% \pm 1.42 \%)$. The proportion of CD4+CD44+ cells in the spleen of HFD treated mice was significantly higher than in the normal control group $(\mathrm{P}<0.05)$. Both the $\mathrm{AS}+$ Compound $\mathrm{C}$ group and the AS + A-769662 group had significantly reduced proportion of CD4+CD44+ lymphocytes in the spleen as compared to the AS group and AS + solvent group $(\mathrm{P}<0.05)$ (Table 2, Figure 3). This is suggested that AMPK may affect the proliferation rate of memory $\mathrm{T}$ cells, which is more pronounced after AMPK inhibitor (Compound C) treatment.

\section{Detection of AMPK expression in the spleen}

There was no significant difference in the expression of AMPK- $\alpha$ between the normal control group and the AS group $(\mathrm{P}>0.05)$. $\mathrm{p}$-AMPK expression in the healthy mice was significantly higher than that in the HFD treated mice 
A

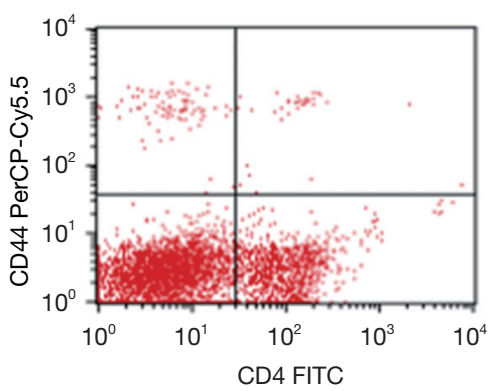

\begin{tabular}{cccc} 
Quad & Events & $\%$ Gated & \% total \\
\hline UL & 449 & 2.09 & 1.97 \\
UR & 159 & 0.74 & 0.70 \\
LL & 15,418 & 71.91 & 67.77 \\
LR & 5,414 & 25.25 & 23.80
\end{tabular}

D

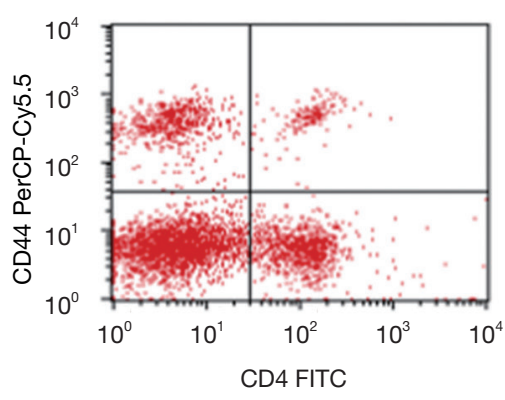

Quad Events \% Gated \% total

$\begin{array}{llll}\text { UL } & 2,687 & 12.56 & 11.88\end{array}$

$\begin{array}{llll}\text { UR } & 848 \quad 3.96 \quad 3.75\end{array}$

LL $\quad 13,035 \quad 60.92 \quad 57.65$

LR $\quad 4,827 \quad 22.56 \quad 21.35$
B

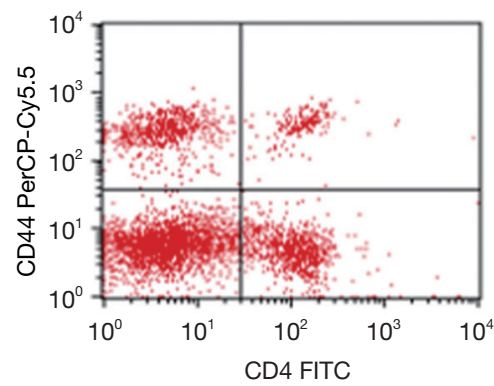

\begin{tabular}{cccc} 
Quad & Events & $\%$ Gated $\%$ total \\
\hline UL & 3,639 & 16.81 & 15.87
\end{tabular}

$\begin{array}{llll}\text { UR } & 1,098 \quad 5.07 \quad 4.79\end{array}$

LL $\quad 12,427 \quad 57.42 \quad 54.21$

LR $\quad 4,479 \quad 20.69 \quad 19.54$

E

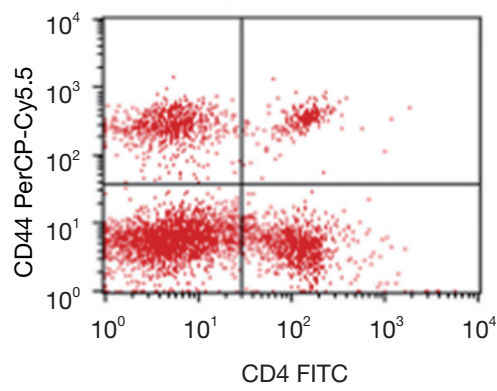

\begin{tabular}{cccc} 
Quad & Events & $\%$ Gated & $\%$ total \\
\hline UL & 3,595 & 16.61 & 15.66 \\
UR & 1,165 & 5.38 & 5.08 \\
LL & 12,185 & 56.28 & 53.09 \\
LR & 4,704 & 21.73 & 20.49
\end{tabular}
C

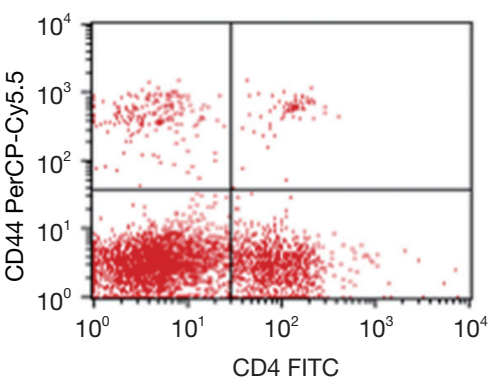

\begin{tabular}{cccc} 
Quad & Events & \% Gated \% total \\
\hline UL & 922 & 4.29 & 4.04
\end{tabular}

$\begin{array}{lll}\text { UR } & 320 \quad 1.49 \quad 1.40\end{array}$

LL $\quad 14,917 \quad 69.45 \quad 65.31$

LR $\quad 5,320 \quad 24.77 \quad 23.29$

Figure 3 Flow cytometry of spleen CD4+CD44+ lymphocytes in different groups. AMPK affected the proliferation rate of memory T cells, which was more pronounced after AMPK inhibitor (Compound C) treatment. (A) Normal control group; (B) AS model group; (C) AS + Compound C group; (D) AS + A-769662 group; (E) AS + solvent group. AS, atherosclerosis.

$(\mathrm{P}<0.05)$. The p-AMPK expression reduced significantly in the AS + Compound $\mathrm{C}$ group $(\mathrm{P}<0.05)$ as compared to the AS group and AS + solvent group. The p-AMPK expression in the AS + A-769662 group was markedly higher than in the AS group and AS + solvent group (Figure 4). This is suggested that $\mathrm{p}-\mathrm{AMPK}$ is better than AMPK- $\alpha$ in reflecting the AMPK activity.

\section{Detection of mTOR expression in the spleen}

There was no significant difference in the mTOR expression between the normal control group and different AS groups. The p-mTOR expression was low in the normal control group, but increased in four HFD groups. The p-mTOR expression in the AS + Compound C group increased significantly as compared to other three AS groups $(\mathrm{P}<0.05)$; in the AS + A-769662 group, p-mTOR expression was down-regulated as compared to the AS + Compound C group $(\mathrm{P}<0.05)$. There was no significant difference in the expression of $\mathrm{p} 70 \mathrm{~S} 6 \mathrm{~K}$, a downstream product of $\mathrm{mTOR}$, between the normal control group and the AS group. The p-p70S6K had a weak expression in the normal control group; the p-p70S6K expression in the AS + A-769662 group significantly reduced as compared to the AS + Compound $\mathrm{C}$ group $(\mathrm{P}<0.05)$. There was no significant difference in the eIF4E $(50 \mathrm{kD})$ expression between the normal control group and AS groups. 4EBP1 expression was low in the normal control group; the 4EBP1 expression 

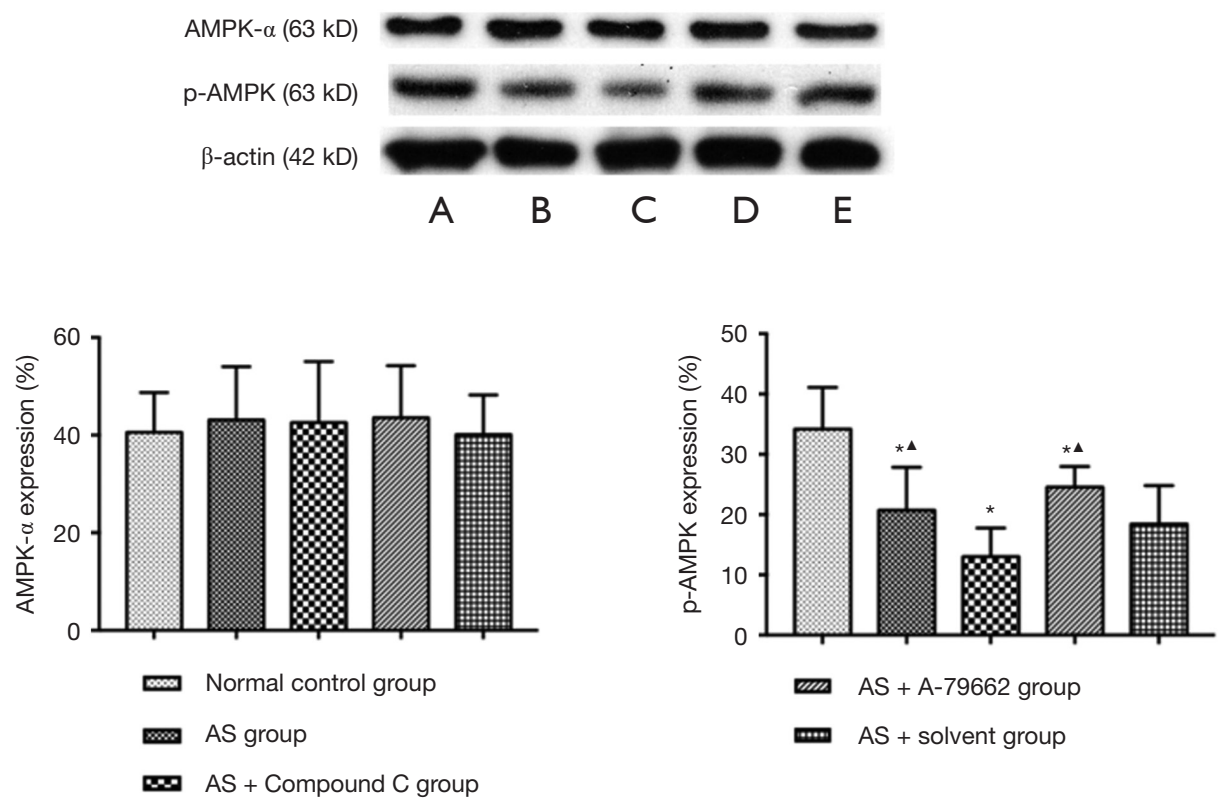

Figure 4 Expression of AMPK and p-AMPK in the spleen (Western blotting). p-AMPK was better than AMPK- $\alpha$ in reflecting the AMPK activity. (A) Normal control group; (B) AS group; (C) AS + Compound C group; (D) AS + A-769662 group; (E) AS + solvent group. AS, atherosclerosis. ${ }^{*} \mathrm{P}<0.05$ vs. normal control group. ${ }^{\boldsymbol{}} \mathrm{P}<0.05$ : vs. $\mathrm{AS}+\mathrm{Compound} \mathrm{C}$ group.

in the AS + A-769662 group was markedly lower than in the AS + Compound $\mathrm{C}$ group $(\mathrm{P}<0.05)$ (Figure 5). mTOR is a key factor involved in the anabolism and catabolism of T cells, and p-mTOR, p70S6K, p-p70S6K, 4EBP1 and eIF4E are important downstream factors of $\mathrm{mTOR}$. There is evidence showing that inhibition of $\mathrm{mTOR}$ is able to promote the catabolism in the $\mathrm{T}$ cells, which increases the production of memory $\mathrm{T}$ cells $(9,10)$. However, as a protective response to complete inhibition of mTOR, the naïve $T$ cells cannot be activated to proliferate. HFD is able to increase memory $\mathrm{T}$ cell production, inducing AS. However, inhibition of AMPK may activate the mTOR pathway, leading to the increased cellular anabolism and reduced catabolism, increasing the memory $\mathrm{T}$ cells.

\section{Discussion}

T lymphocytes play a key role in the immune process during the initiation of AS (11-13). Animal studies have shown that inhibition of chemokine receptors such as CRR5H and CXCR3 $(14,15)$ on the $T$ cells in the atherosclerotic plaques can attenuate the progression of AS. The CD4+ memory $\mathrm{T}$ lymphocytes and CD8 +memory $\mathrm{T}$ lymphocytes have been identified in patients with and without coronary heart disease and there is significant difference in the number of CD4+ memory $\mathrm{T}$ cells between them although the number of CD8+ memory $\mathrm{T}$ cells is comparable (16-18). There was significant difference in the proportion of CD4+ lymphocytes, but there was no difference in the proportion of CD8+ memory $\mathrm{T}$ lymphocytes. This suggests CD4+ memory $\mathrm{T}$ lymphocytes play a more critical role in the development of AS. In AS, antigens formed in the hyperlipidemia environment (19) may affect or stimulate the central memory $\mathrm{T}$ cells and effector memory cells. The immune memory is an integral part of adaptive immunity to ensure long-lasting protection against previously encountered pathogens. The advantage of immune memory is that it can quickly and strongly initiate an immune response when the body faces the similar antigen in the future. The pathogenesis of AS is considered to be related to the immune mediated inflammatory response, and immune memory is closely associated with the occurrence and development of AS.

AMPK has been identified as a potential new therapeutic target for cardiovascular disorders (20-22). In addition, AMPK possesses the capability to regulate $T$ cells and is involved in the anti-inflammatory immune responses (23). AMPK is mainly present in two active molecules: AMPK- $\alpha$ and p-AMPK. In the present study, results showed AMPK activity changed significantly in AS mice. The p-AMPK 

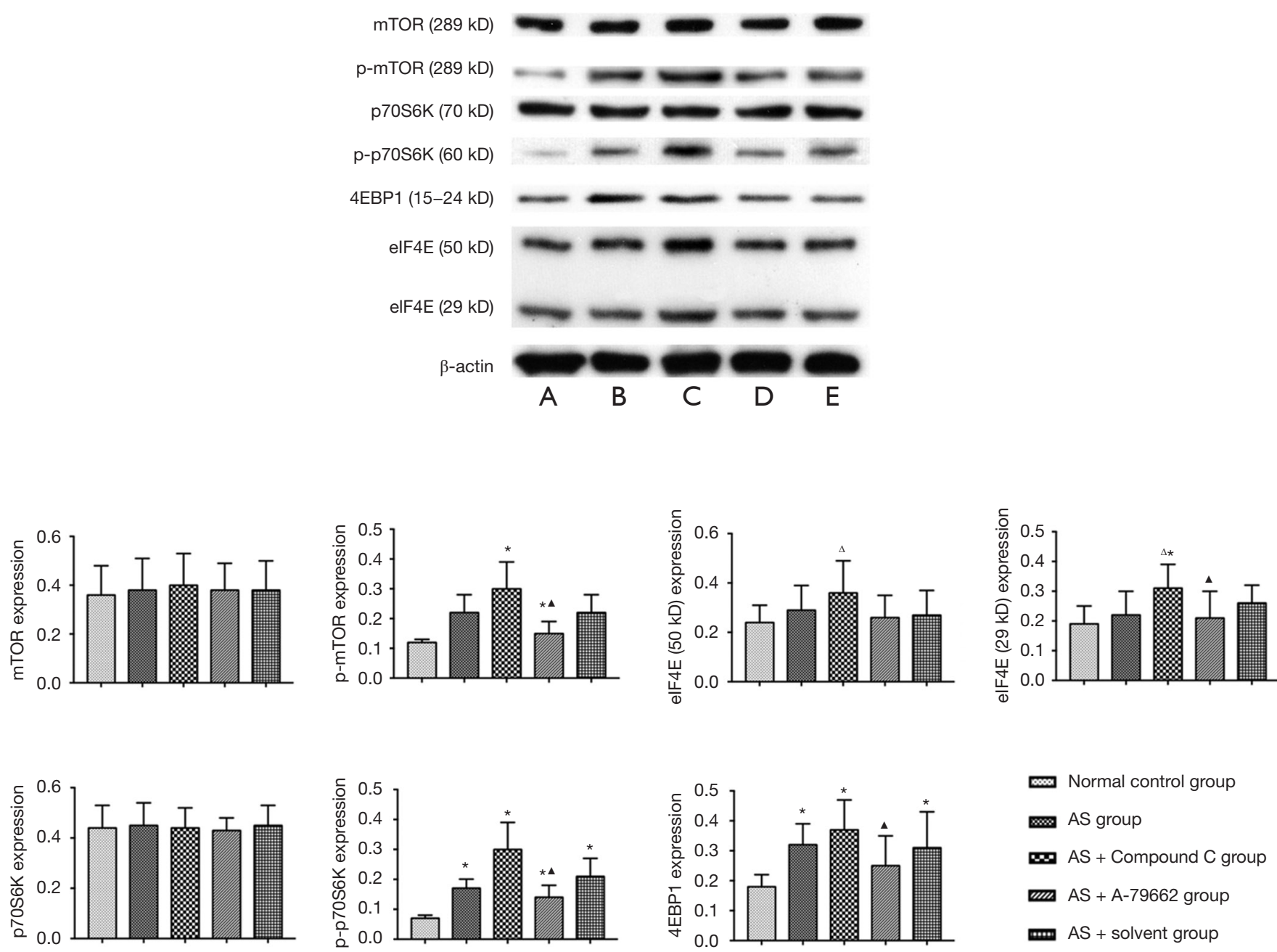

Figure 5 Expression of molecules in mTOR pathway in the spleen (Western-blotting). *, $\mathrm{P}<0.05$ vs. normal control group; ${ }^{\boldsymbol{}}, \mathrm{P}<0.05$ vs. AS + Compound $\mathrm{C}$ group. ${ }^{\Delta}, \mathrm{P}<0.05$ vs. AS group $(\mathrm{P}<0.05)$.

expression was down-regulated, while the AMPK- $\alpha$ expression remained unchanged. This suggests that p-AMPK is more sensitive than AMPK- $\alpha$ in reflecting the AMPK activity. The p-AMPK expression was further downregulated after Compound $\mathrm{C}$ treatment in the HFD treated mice, while the AMPK- $\alpha$ expression still remained stable. However, the p-AMPK expression increased significantly after A-769662 treatment in the HFD treated mice, but the AMPK- $\alpha$ expression maintained stable. These findings indicate $\mathrm{p}$-AMPK is superior to AMPK $\alpha$ in reflecting AMPK activity in case of HFD treatment.

AS is a chronic inflammation and ox-LDL persists in the development of AS. T cells may produce immunological memory after initial contact with ox-LDL. This immune memory may promote or inhibit the development of AS, but this hypothesis is needed to be further confirmed. The production of CD4+CD44+ memory $\mathrm{T}$ cells may be a double-edged sword for AS. With the continuous increase in the CD4+CD44+ $\mathrm{T}$ cells, the AS is not improved significantly; with the reduction in the CD4+CD44+ $\mathrm{T}$ cells, the improvement of AS is also compromised; the moderate proportion of $\mathrm{CD} 4+\mathrm{CD} 44+\mathrm{T}$ cells is protective on AS. From the perspective of immunology: memory $T$ cells increase after the activation, proliferation and differentiation of naïve $T$ lymphocytes following exposure to the immunogen. When exposed to the same immunogen again, memory $\mathrm{T}$ cells will quickly trigger an immune response to clear the immunogen, exerting protective effects. When the immunogen persists, the immune response will be too long or too strong, which may lead to 
the hypersensitive reaction, causing damage to the body. Therefore, it is possible that memory $\mathrm{T}$ cells play a dual role.

The differentiation of $\mathrm{T}$ cells is dependent on the microenvironment. After $\mathrm{T}$ cell activation, mitochondrial metabolism is required to maintain the energy need and the survival of T cells. During this period, the survival of $\mathrm{T}$ cells is regulated by AMPK as an energy receptor. Available studies have indicated that AMPK acts as a "metabolic shield" in a poor environment. Thus, AMPK may ensure cell viability when there is nutrient deficiency (e.g., tumor microenvironment: hypoxia and glucose deficiency) (23-26).

In the present study, results showed that the proportion of CD4+CD44+ $\mathrm{T}$ cells in the spleen of the HFD treated mice was significantly higher than in the normal control group. The proportion of CD4+CD44+ $\mathrm{T}$ cells in the spleen of the Compound $\mathrm{C}$ group and the A-769662 group was markedly lower than in the AS group, and the decline was more pronounced in the A-769662 group.

This may be explained that, in the HFD environment, cells are excessively oxidized, the p-AMPK expression is down-regulated, and the proportion of $\mathrm{T}$ cells differentiating into CD4+CD44+ memory $\mathrm{T}$ cells increases. AMPK has the capability to alter the differentiation of $\mathrm{T}$ cells in an unfavorable environment. After Compound $\mathrm{C}$ treatment, p-AMPK expression significantly decreased, while p-mTOR expression increased, and the expression of p-p70S6K, 4EBP1, and eIF4E significantly enhanced, thereby markedly inhibiting the formation of CD4+CD44+ T cells. A-769662 up-regulated the p-AMPK expression and down-regulated the expression of p-mTOR, p-p70S6K, 4EBP1, and eIF4E. However, in the complex in vivo environment, AMPK pathway fails to further promote the formation of memory $\mathrm{T}$ cells, but reduces memory $\mathrm{T}$ cells in the presence of high risk for AS, which alleviates the immune inflammatory response, exerting protective effects. Because Compound $\mathrm{C}$ is able to reversibly inhibit AMPK inhibitor, AMPK inhibitor regulates the expression of mTOR downstream proteins in memory $\mathrm{T}$ cells, which is different between in vivo environment and in vitro environment. This might be explained as that AMPK is a reversible inhibitor of compound $\mathrm{C}$ and can inhibit several enzymes, which may affect different downstream pathways.

\section{Conclusions}

In conclusion, our study shows that the proportion of CD4+CD44+ memory $\mathrm{T}$ cells in the spleen of AS mice is significantly higher than in the healthy mice. After intervention of the AMPK activity, the proportion of CD4+CD44+ memory $\mathrm{T}$ cells in the spleen of AS mice reduces, which is accompanied by the improvement of AS, but only the moderate proportion of CD4+CD44+ T cells can achieve a better immune protection. Moreover, the regulation of $\mathrm{AMPK}$ activity also affects the protein expression of $\mathrm{p}-\mathrm{mTOR} / \mathrm{p}-\mathrm{p} 70 \mathrm{~S} 6 \mathrm{~K} / 4 \mathrm{EBP} 1 / \mathrm{eIF} 4 \mathrm{E}$.

Our study indicates that p-mTOR/p-p70S6K/4EBP1/ eIF4E signaling pathway may be a potential therapeutic target in the prevention and/or treatment of AS. However, it is needed to explore the optimal timing of AMPK intervention and the optical level of AMPK for memory $T$ cell proliferation as well as the optimal proportion of memory $\mathrm{T}$ cells in the prevention and treatment of AS.

\section{Acknowledgments}

Funding: This study was supported by the National Natural Science Foundation of China (NO81570451, NO81570271 and NO81370649), and the Science and Technology Department of Hunan Province (NO2010FJ3104).

\section{Footnote}

Conflicts of Interest: The authors have no conflicts of interest to declare.

Etbical Statement: The authors are accountable for all aspects of the work in ensuring that questions related to the accuracy or integrity of any part of the work are appropriately investigated and resolved. This study was approved by the Institutional Ethics Committee of the Third Xiangya Hospital of Central South University (No: 2015-S175).

\section{References}

1. Hansson GK, Holm J, Jonasson L. Detection of activated T lymphocytes in the human atherosclerotic plaque. Am J Pathol 1989;135:169-75.

2. Stemme S, Holm J, Hansson GK. T lymphocytes in human atherosclerotic plaques are memory cells expressing CD45RO and the integrin VLA-1. Arterioscler Thromb 1992;12:206-11.

3. Mayr M, Metzler B, Kiechl S, et al. Endothelial cytotoxicity mediated by serum antibodies to heat shock proteins of Escherichia coli and Chlamydia pneumoniae: 
immune reactions to heat shock proteins as a possible link between infection and atherosclerosis. Circulation 1999;99:1560-6.

4. Stemme S, Faber B, Holm J, et al. T lymphocytes from human atherosclerotic plaques recognize oxidized low density lipoprotein. Proc Natl Acad Sci U S A 1995;92:3893-7.

5. Stemme S, Rymo L, Hansson GK. Polyclonal origin of T lymphocytes in human atherosclerotic plaques. Lab Invest 1991;65:654-60.

6. Olson NC, Doyle MF, Jenny NS, et al. Decreased naive and increased memory CD4(+) $\mathrm{T}$ cells are associated with subclinical atherosclerosis: the multi-ethnic study of atherosclerosis. PLoS One 2013;8:e71498.

7. Kondo M, Shibata R, Miura R, et al. Caloric restriction stimulates revascularization in response to ischemia via adiponectin-mediated activation of endothelial nitric-oxide synthase. J Biol Chem 2009;284:1718-24.

8. Ma A, Wang J, Yang L, et al. AMPK activation enhances the anti-atherogenic effects of high density lipoproteins in apoE(-/-) mice. J Lipid Res 2017;58:1536-47.

9. Araki K, Turner AP, Shaffer VO, et al. mTOR regulates memory CD8 T-cell differentiation. Nature 2009;460:108-12.

10. Pearce EL, Walsh MC, Cejas PJ, et al. Enhancing CD8 T-cell memory by modulating fatty acid metabolism. Nature 2009;460:103-7.

11. Brown MS, Goldstein JL. Familial hypercholesterolemia: defective binding of lipoproteins to cultured fibroblasts associated with impaired regulation of 3-hydroxy-3methylglutaryl coenzyme A reductase activity. Proc Natl Acad Sci U S A 1974;71:788-92.

12. Hansson GK, Hermansson A. The immune system in atherosclerosis. Nat Immunol 2011;12:204-12.

13. Libby P, Ridker PM, Maseri A. Inflammation and atherosclerosis. Circulation 2002;105:1135-43.

14. Mach F, Sauty A, Iarossi AS, et al. Differential expression of three T lymphocyte-activating CXC chemokines by human atheroma-associated cells. J Clin Invest 1999; 104:1041-50.

15. van Loosdregt J, van Oosterhout MF, Bruggink AH,

Cite this article as: Peng LP, Cao Y, Zhao SL, Huang YX, Yang K, Huang W. Memory T cells delay the progression of atherosclerosis via AMPK signaling pathway. Ann Transl Med 2019;7(23):782. doi: 10.21037/atm.2019.11.20 et al. The chemokine and chemokine receptor profile of infiltrating cells in the wall of arteries with cardiac allograft vasculopathy is indicative of a memory T-helper 1 response. Circulation 2006;114:1599-607.

16. Gertler MM, Oppenheimer BS. The total cholesterollipid phosphorus ratio; its significance in atherosclerosis. Geriatrics 1954;9:157-62.

17. Goldstein JL, Brown MS. A century of cholesterol and coronaries: from plaques to genes to statins. Cell 2015;161:161-72.

18. Zhang X, Niessner A, Nakajima T, et al. Interleukin 12 induces T-cell recruitment into the atherosclerotic plaque. Circ Res 2006;98:524-31.

19. Sallusto F, Geginat J, Lanzavecchia A. Central memory and effector memory $T$ cell subsets: function, generation, and maintenance. Annu Rev Immunol 2004;22:745-63.

20. Hardie DG. AMPK and Raptor: matching cell growth to energy supply. Mol Cell 2008;30:263-5.

21. Suzuki K, Uchida K, Nakanishi N, et al. Cilostazol activates $\mathrm{AMP}$-activated protein kinase and restores endothelial function in diabetes. Am J Hypertens 2008;21:451-7.

22. Zou MH, Hou XY, Shi CM, et al. Activation of $5^{\prime}$-AMP-activated kinase is mediated through c-Src and phosphoinositide 3-kinase activity during hypoxiareoxygenation of bovine aortic endothelial cells. Role of peroxynitrite. J Biol Chem 2003;278:34003-10.

23. O'Neill LA, Hardie DG. Metabolism of inflammation limited by AMPK and pseudo-starvation. Nature 2013;493:346-55.

24. Chang CH, Qiu J, O'Sullivan D, et al. Metabolic Competition in the Tumor Microenvironment Is a Driver of Cancer Progression. Cell 2015;162:1229-41.

25. Kim Y, Lin Q, Glazer PM, et al. Hypoxic tumor microenvironment and cancer cell differentiation. Curr Mol Med 2009;9:425-34.

26. Navratilova J, Hankeova T, Benes P, et al. Low-glucose conditions of tumor microenvironment enhance cytotoxicity of tetrathiomolybdate to neuroblastoma cells. Nutr Cancer 2013;65:702-10. 